\title{
Morphometric studies of the craniofacial region of the African sideneck turtle (Pelusios castaneus)
}

\author{
IGADO, O. O. *, OLUKOLE, S. G. and OKE, B. O. \\ Department of Veterinary Anatomy, Faculty of Veterinary Medicine, University of Ibadan, Nigeria \\ ${ }^{*}$ E-mail: mayowaigado@yahoo.com
}

\begin{abstract}
Introduction and Methods: Morphometric analysis of the craniofacial regions of the African sideneck turtle (Pelusios castaneus) were carried out with the aim of generating data which could be useful in wildlife veterinary clinical practice as well as in the comparative regional anatomy of turtles. Results: The average weight of turtles used for this study was $0.51 \pm 0.39 \mathrm{~kg}$, while the mean weight of head was $20 \pm 6.50 \mathrm{~g}$. The mean palpebral fissure lengths for the left and right eyes were $0.75 \pm 0.10$ and $0.77 \pm 0.11 \mathrm{~cm}$ respectively, while the orbital heights of the left and right eyes and the distance between the medial canthi were $0.74 \pm 0.11,0.75 \pm 0.11$ and $0.59 \pm 0.10 \mathrm{~cm}$ respectively. Out of the twenty parameters measured, only four showed statistically significant difference $(\mathrm{P}<0.05)$ between the sexes, with the male values being higher in all the four cases. There were strong positive correlations between the left and right lengths of palpebral fissure $(r=0.959)$ and between the left and right orbital heights $(\mathrm{r}=0.964)$. Conclusion: The data obtained in this study, being the first report on craniofacial indices of the African sideneck turtle, is expected to serve as baseline data on the craniofacial anatomy of the animal and hence in the comparative regional anatomy of both fresh water and sea turtles.
\end{abstract}

Keywords: Pelusios castaneus, craniofacial indices, African sideneck turtle, eyeball, morphometry.

\section{Introduction}

The African sideneck turtle (Pelusios castaneus) (Figures 1 and 2) belongs to the family Pelomedusidae, and is the largest species of its genus (carapace length up to $55 \mathrm{~cm}$ ) (BROADLEY and BOYCOTT, 2009). It is small to medium in size, with a relatively extensive plastron that may have a hinge present between the pectoral and abdominal scutes (OLUKOLE, AINA and OKUSANYA, 2010), and the females are larger than the males (BROADLEY and BOYCOTT, 2009). It is usually found in freshwater habitats, from rivers and lakes to ephemeral ponds being widely distributed in Africa, Madagascar and the Seychelle Islands (ANDERSON, 1995). The neural series is highly variable (four to eight), and the pleural bones almost meet the midline posterior to the neurals. A pair of mesoplastral bones is present between the hyo- and hypoplasta (BOYCOTT and BOURQUIN, 2000). These turtles are occasionally eaten by indigenous people, but their foul-smelling musk secretions probably serve to discourage more regular consumption. They are also low in demand for pet trade (BOYCOTT and BOURQUIN, 2000).

Regional anatomy of the head is an important aspect of gross anatomy showing the spatial relationship of the organs in that region and had been extensively used in forensive archaeology. Craniofacial indices in humans have been useful in the early detection, diagnosis and study of the development of the characteristic facial appearance of some syndromes like the Williams syndrome (HOVIS and BUTLER, 1997).

Previous studies on the African sideneck turtle had focused mainly on its conservation, nutrition and history of migration (BROADLEY and BOYCOTT, 2009) and the morphometry of the external body anatomy (OLUKOLE, AINA and OKUSANYA, 2010). Values for some craniofacial indices have been reported in other animals like the horse, cattle, dogs, cats and different breeds of goats (GELATT, 1981; OLOPADE, ONWUKA, KWARI et al., 2005), but so far none on the African sideneck turtle. This study was therefore designed to investigate the morphometry of the craniofacial region of the African sideneck turtle with the aim of obtaining information that would not only serve as a baseline data on the skull of the animal, but also be of importance in veterinary clinical practice, anthropological studies, and also in species and breed identification.

\section{Materials and Methods}

Twenty adult turtles of both sexes were used for this study. They were obtained from different streams and rivers within the rural areas of Ibadan, Oyo State, Nigeria. They were stabilised in artificial ponds for one week during which locally made corn meal and water were given ad libitum. The turtles were weighed using a Microwa ${ }^{\circledR}$ weighing balance, anaesthetized and sacrificed by quick cervical decapitation as previously described (OLUKOLE, OYEYEMI and OKE, 2009). Craniofacial parameters were all determined using a Draper® $115 \mathrm{~mm}$ vernier caliper, a piece of twine and a metric rule with measurements taken to the nearest $0.05 \mathrm{~cm}$. All measurements were taken on the fresh specimen. The eyeballs were removed according to the method described by Igado (2011). Periorbital fat and muscular attachments were removed and measurements taken immediately. The eyeballs were weighed using My weigh i201@ digital weighing balance and ocular dimensions were measured using a thin twine, the length of which was measured with a vernier caliper to get the exact measurement to the nearest $0.05 \mathrm{~cm}$. 


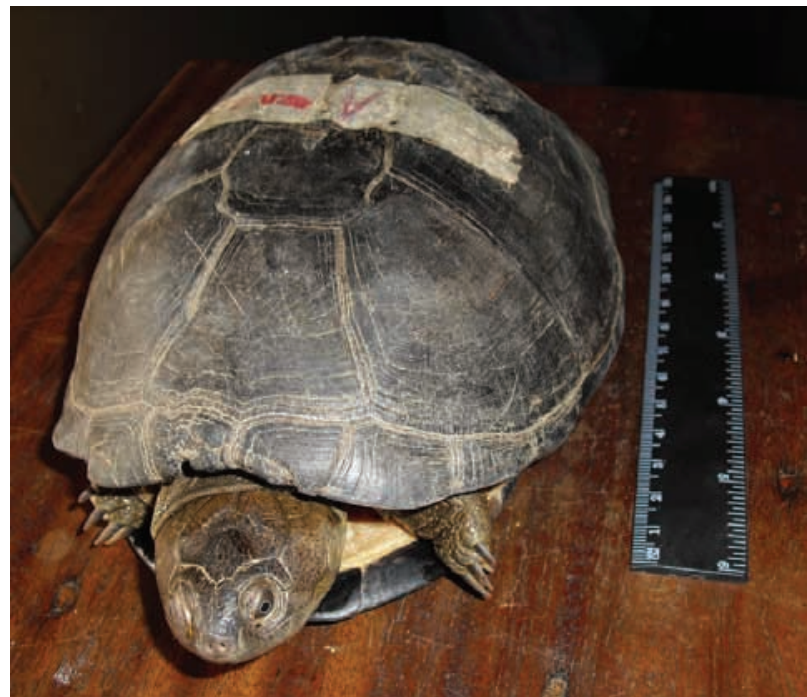

Figure 1. Rostro-dorsal view of the African sideneck turtle (Pelusios castaneus).



Figure 2. Rostro-dorsal view of the African sideneck turtle (Pelusios castaneus) (head retracting into shell).

The parameters taken and their anatomical landmarks were:

- Distance between Medial Canthi (DMC): distance between the medial canthi of the right and left eyes, across the dorsal aspect of the prefrontal bones.

- Rima Oris Length (ROL): distance between the right and the left rhamphotheci (lips) commisures. This was done with the aid of a piece of twine, which was then measured against a metric rule.

- Palpebral Fissure Length of the Left and Right eyes (PFLL and PFLR respectively): distance between the medial and lateral canthi of each eye. This was measured with the aid of vernier callipers.

- Height of External Nares (ENH): maximum distance between the dorsal and ventral borders of the external nares, measured with the aid of vernier callipers.
- Width of External Nares (ENW): maximum distance between the right and left lateral borders of the external nares, measured with the aid of vernier callipers.

- Orbital Height of the Left and Right eyes (OHL and $O H R$ respectively): This is the height of the orbits, measured along the dorso-ventral axis.

- Length of Head (LOH): distance from the tip of the external nares (which is the most rostral point of the head) to the fold of the neck, located immediately caudal to the supraoccipital bone of the skull. Measured with the aid of vernier callipers.

- Width of the Head (WiOH): maximum width of the head, measured as the distance between the right lateral and the left lateral sides, across the jugal/ zygomatic bones, with the aid of vernier callipers.

- Dorso-Ventral Circumference of Eyeball (Right and Left -REDV AND LEDV respectively): maximum circumference of the eyeball across the dorso-ventral axis (position of upper and lower eyelids).

- Medio-Lateral circumference of Eyeball (Right and Left- REML and LEML respectively): maximum circumference of the eyeball, across the medio-lateral axis (position of the medial and lateral canthi).

- Peri-Orbital circumference (Right and Left - REPO and LEPO respectively): maximum circumference of eyeball peri-orbitally.

All data were presented as Mean \pm Standard deviation. Statistical analysis was done using Student's t-test and correlation analysis. Statistical significance was reported at $\mathrm{p}<0.05$.

\section{Results}

Data obtained are presented in Tables 1 and 2, and expressed as Mean \pm Standard deviation.

The average weight of turtles used for this study was $0.51 \pm 0.39 \mathrm{~kg}$, while the mean weight of head was $20 \pm 6.5$ grams (Table 1 ). The heads of the turtles were dorsoventrally flattened in the characteristic reptilian disposition with no gross distinguishing craniofacial features between the males and females. The orbits were almost spherical in shape with a slight notch on the medial aspect. The eyelids were dorsoventrally oriented, forming a vertical, longitudinal slit. The males showed consistently higher values for the craniofacial parameters observed, despite the fact that the body weights of the males were lower than the females (Table 2).

The mean values for the rima oris length, distance between medial canthus, palpebral fissure lengths (left and right), orbital heights (left and right) for the males were 3.70 $\pm 0.37 \mathrm{~cm}, 0.60 \pm 0.08 \mathrm{~cm}, 0.79 \pm 0.08 \mathrm{~cm}, 0.82 \pm 0.10 \mathrm{~cm}$, $0.77 \pm 0.10 \mathrm{~cm}$, and $0.80 \pm 0.09 \mathrm{~cm}$ respectively; while those of the females were $3.30 \pm 0.56,0.58 \pm 0.12,0.72 \pm 0.10$, $0.73 \pm 0.10,0.71 \pm 0.11,0.70 \pm 0.11 \mathrm{~cm}$ respectively, (Table 2 ). The values for the external nares width, orbital height of the right eye, length of the head and width of the head were significantly higher $(\mathrm{p}<0.05)$ in the males than in the females (Table 2). Although, the eyeball measurements (weight, medio-lateral, dorso-ventral, and peri-orbital circumference) were slightly higher in the males, no statistically significant differences were observed $(\mathrm{P}>0.05)$ (Table 2$)$. There were strong positive correlations between the left and right 


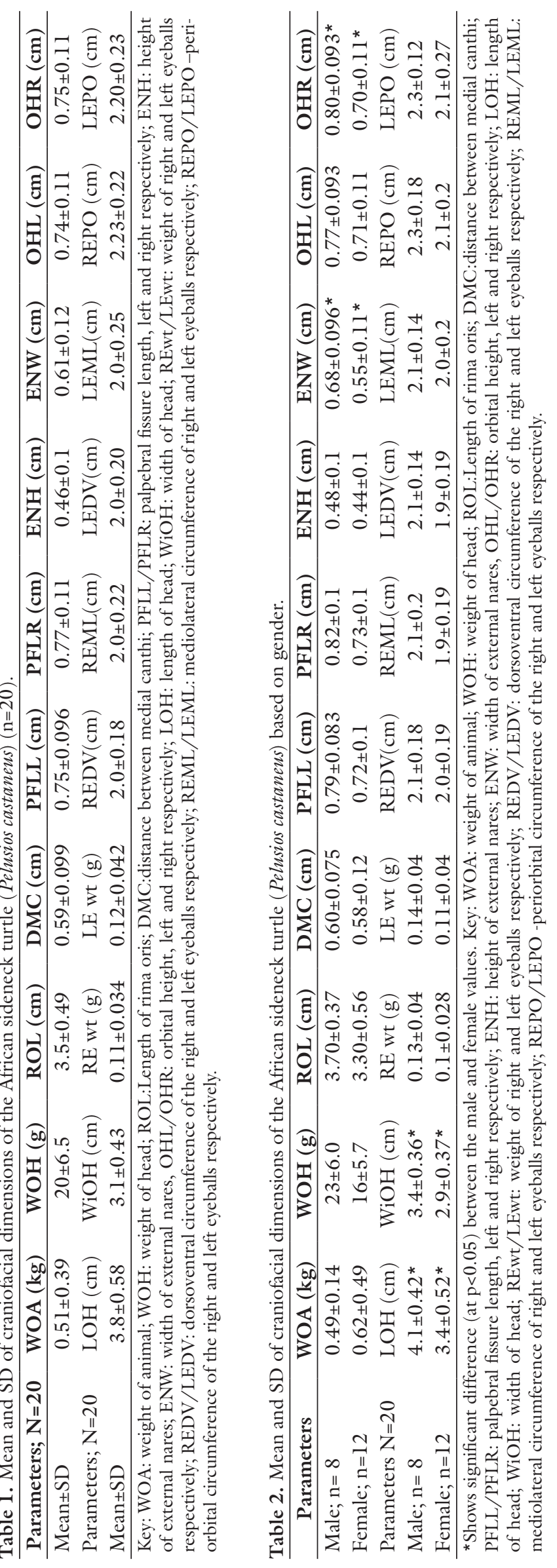


palpebral fissure lengths $(r=0.959)$ and between the left and right orbital height $(\mathrm{r}=0.964)$. Also, a strong positive correlation occurred between the palpebral fissure lengths (PFL) and the dorsoventral circumference of the eye $(\mathrm{r}=0.855$-left; $\mathrm{r}=0.720$ - right $), \mathrm{PFL}$ and the mediolateral circumference $(r=0.727$-left; $r=0.846$ - right), PFL and peri-orbital circumference $(\mathrm{r}=0.832$-left; $\mathrm{r}=0.90$ - right $)$, and PFL and eye weight $(r=0.787$-left; $r=0.870$ - right $)$.

\section{Discussion}

Generally, the females used for this study were observed to have a higher body weight relative to the males. All other parameters measured showed consistently higher values in the males relative to the females, but statistically significant differences $(\mathrm{P}<0.05)$ were only observed in the width of the external nares, orbital height of the right eye, length and width of the head.

The males had a higher head weight-body weight ratio of $4.69 \%$ while that of the females was $2.58 \%$. The fact that the males have a relatively higher WOH:WOA index was also reflected in the higher values obtained for the other indices in the males. The greater values obtained for the DMC, PFLL, PFLR values in male, relative to the females show that the eyes in the males are more laterally placed. This could be an adaption for the protective role of the male, as hunted animals have been shown to have their eyes placed more laterally (DYCE, SACK and WENSING, 2002) to enable them see over a wider range. This can also account for the higher orbital height and palpebral fissure values obtained in the males.

The slight asymmetry observed in the palpebral fissure lengths and orbital heights of the right and left eyes is consistent with the report of Getty, (1975) that asymmetry occurs between the two halves of the animal body. Also, the relatively higher value obtained for the rima oris length (ROL) in the males $(3.7 \pm 0.37)$, relative to the females $(3.3 \pm 0.56)$. Although the difference in the ROL is not statistically significant, the higher value obtained may be a morpho-physiological adaptation implying that the males are more voracious eaters. Further studies will have to be carried out on the feeding habits of this species to ascertain this. The relatively heavier body weight in the females may be due to the presence of eggs in the body since all the animals used were adults. The average width and length of the head of the males obtained in this study corresponds to that obtained by Olukole, Aina and Okusanya (2010) in the male African sideneck turtle.

The weight of the two eyeballs in the males accounted for $0.06 \%$ of the body weight, while that of the females accounted for $0.03 \%$. This disparity in spite of the statistically non-significant difference $(P>0.05)$ observed in the eyeball weights is probably due to the difference in body weight. The eyeball measurements did not show any sexual dimorphism as the results obtained were similar in both sexes (Table 2).

Although this study of the craniofacial indices did not reveal any distinguishing feature on the head that is peculiar to either gender, the hard carapace on the dorsal aspect reveals a more dome-shape appearance in the females relative to the males.

With the present increasing interest in wildlife species, this report, the first of its kind on the craniofacial indices of the African sideneck turtle, is expected to serve as baseline data on the craniofacial anatomy and comparative regional anatomy of fresh water and sea turtles, and also aid wildlife veterinary clinicians, especially in ophthalmic surgical manipulations.

\section{References}

ANDERSON, NB. Life history notes. Pelusios sinuatus: reproduction. African Herp News, 1995, vol. 23, p. 49.

BROADLEY, DG. and BOYCOTT, RC. Pelusios simuatus (Smith 1838 ) - serrated hinged terrapin. In RHODIN, AGJ., PRITCHARD, PCH., VAN DIJK, PP., SAUMURE, RA., BUHLMANN, KA., IVERSON, JB. and MITTERMEIER, RA. (Eds.). Conservation biology of freshwater turtles and tortoises: a compilation project of the IUCN/SSC tortoise and Freshwater Turtle Specialist Group. Chelonian Research Monographs, 2009, n. 5, p. 036.1-036.5.

BOYCOTT, RC. and BOURQUIN, O. The Southern African tortoise book: a guide to southern african tortoise, terrapins and turtles. KwaZulu-Natal: O Bourquin, 2000. p. 228.

DYCE, KM., SACK, WO. and WENSING, CJG. Textbook of veterinary anatomy. 3rd ed. Philadelphia: Saunders, 2002.

GELATT, KW. Veterinary ophthalmology. London: Lea and Febiger, 1981.

GETTY, R. Sisson and Grossman's Anatomy of the domestic animals. Rio de Janeiro: Guanabara Koogan, 1975. p. 29-30. vol. 1.

HOVIS, CL. and BUTLER, MG. Photoanthropometric study of craniofacial traits in individuals with Williams syndrome. Clinical Genetics, 1997, vol. 51, n. 6, p. 379-387. PMid:9237500. http:// dx.doi.org/10.1111/j.1399-0004.1997.tb02495.x

IGADO, OO. Gross morphometric study of the eyeball and tongue of the nigerian local dog. Italian Journal of Anatomy and Embryology, 2011, vol. 116, n. 1, p. 104-110. PMid:22303638.

OLOPADE, JO., ONWUKA, SK., KWARI, HD. and FATOLA, OI. Morphometric studies of the craniofacial region of the sahel goat. In Proceedings of the $42 n d$ Annual Congress of the Nigeria Veterinary Medical Association, 2005.

OLUKOLE, SG., OYEYEMI, MO. and OKE, BO. Biometrical observations on the testes and epididymis of the domesticated adult african great cane rat (Thryonomys swinderianus). European Journal of Anatomy, 2009, vol. 13, n. 2, p. 71-75.

OLUKOLE, SG., AINA, OO. and OKUSANYA, BO. Morphometric analysis of the external body anatomy of the African sideneck turtle. In Proceedings of the 30th Annual symposium of the International Sea Turtle Biology and Conservation Society, 2010. Miami: NOAA, 2010 .

Received September 12, 2013 Accepted August 7, 2014 